\title{
La dialéctica entre exigencia social de pluralismo, diversidad de opciones devocionales y exclusividad de fe. ¿Una causa adicional de la secularización?
}

The Dialectic Between the Social Demand for Plurality, the Diverse Devotional Options and the Exclusivity of Belief. An Additional Cause of Secularization?

ENRIQUe Romerales EsPINOSA Universidad Autónoma de Madrid

DOI: http://dx.doi.org/10.15366/bp2018.19.003 Bajo Palabra. II Época. No19. Pgs: 69-86 


\section{Resumen}

La sociedad actual propicia al máximo el pluralismo, entendido como diversidad de ofertas en cualquier ámbito de nuestra vida. Si bien hay esferas en las que tal diversidad es complementaria y enriquecedora, hay otras en los que es alternativa, aunque inclusiva, y aun otras en los que tal diversidad es excluyente. Este es en general el caso de las religiones, especialmente las monoteístas. Sin embargo, la exigencia social de pluralidad irrestricta -que en el ámbito religioso se traduce en una oferta devocional diversa- entra en colisión con la pretensión de exclusividad sin alternativa, propia de muchas religiones. Desde la filosofía, la teología o la teoría social se propicia la actitud pluralista, en consonancia con nuestro tiempo, pero este pluralismo es muy problemático tanto para las confesiones religiosas como para sus devotos. Esta tensión es plausiblemente una más de las causas de la disminución de las creencias y prácticas religiosas en Occidente, uno de los aspectos clave de la secularización, y en el que la Ilustración y la ciencia han tenido una notable influencia, pese a las reservas al respecto manifestadas por ciertos académicos.

Palabras clave: pluralismo, diversidad, religión, creencia, secularización, devoción, ciencia.

\section{Abstract}

Contemporary society fosters pluralism unrestrictedly, taken as diversity of options on offer in any sphere of life. Even though in some areas such diversity is complementary and enriching, there are others in which it is alternative, yet inclusive, and still other ones where such diversity is selective. This is usually the case with religions, especially with the monotheistic ones. The social demand for unrestricted plurality -that in the religious field turns into diverse devotional options on offer-collides with the demand of exclusivity with no alternatives, that is peculiar to religions. Philosophy, theology or social theory promote a pluralist attitude congenial to our times, but this pluralism is highly problematic both for religious denominations and their devotes. This strain is plausibly an additional cause for the decrease of religious beliefs and practices in the Western world, one of the key facets of secularisation, decrease significantly influenced by the Enlightenment and science, in spite of reservations in this regard put forward by certain scholars.

Keywords: pluralism, diversity, religion, belief, secularisation, devotion, science. 
$\mathrm{E}$ pluralismo en los diversos ámbitos de la sociedad es un rasgo característico de las sociedades contemporáneas imbuidas de los valores occidentales. Así, en ellas existe pluralismo en el ámbito político, en las orientaciones sexuales, en las ideologías, en las opciones gastronómicas, en las actividades deportivas y, cómo no, también en las creencias y actitudes religiosas. En esta lista rapsódica hay, sin embargo, una importante diferencia entre tres tipos de casos. En primer lugar, aquellos en los que es posible, incluso recomendable, seleccionar varias opciones que son no solamente compatibles entre sí, sino incluso complementarias. De este modo, podemos practicar deportes diferentes para mantenernos en forma o divertirnos, vestir de formas diversas en situaciones y circunstancias cambiantes o degustar comidas de tradiciones culinarias harto distintas sin que ello suponga inconveniente; más bien al contrario, tal pluralidad nos resulta algo enriquecedor. Y enriquecedor es siempre el conocimiento de lo ajeno, de lo diverso. Pero, mientras que conocer por ejemplo la gastronomía de diferentes países implica degustarla (o incluso elaborarla), no es factible profesar (en serio) las religiones de tradiciones diversas sin traicionarlas. Podemos conocerlas, y ello será indudablemente provechoso, como podemos conocer ideologías u opciones políticas diferentes a la nuestra, pero sin "comulgar" con ellas.

En segundo lugar, están aquellos casos en los cuales elegir una opción implica rechazar otras. Por ejemplo, si me gusta un deporte, para practicarlo profesionalmente tendré que elegir un club en vez de cualquiera de los demás. Lo mismo ocurre como espectador emocionalmente implicado, como forofo: seguiré y apoyaré a un club (de fútbol, de baloncesto, etc.) o a un deportista (Rafael Nadal, Fernando Alonso, Marc Márquez, etc.) en su disciplina normalmente en régimen de exclusividad, o al menos de preeminencia. Tenemos aquí una elección que es excluyente de las alternativas. Pero, no obstante, en estos casos es a la vez esencial que existan opciones alternativas, porque la esencia del deporte es la competición, y esta solo puede darse allí donde hay varios equipos (o tenistas, corredores, etc.) que puedan competir entre sí, y si es a un nivel equiparable, tanto mejor.

En tercer lugar, se hallan aquellos casos en los que habiendo una pluralidad de opciones y siendo estas alternativas mutuamente excluyentes, sin embargo, el hecho de la pluralidad no solo no es sustancial, sino que resulta en sí mismo problemático. Este es el caso de las religiones, y singularmente en las tradiciones monoteístas. Tanto en el judaísmo desde el Decálogo en el Exodo como en el Corán del islam se insiste en que no se puede adorar más que al Dios que acaba de revelarse. Las demás 
ofertas religiosas son deletéreas, además de falsas. No se trata de competir con ellas reiteradamente ${ }^{1}$ para vencer cuantas más veces mejor (como en una liga o en un campeonato de fútbol o de cualquier otro deporte). Se trata de extirparlas de la faz de la Tierra. Nunca deberían haber existido.

Denominaré al primer tipo de casos el modelo compatibilista, al segundo modelo de rivalidad inclusiva y al tercero modelo de animosidad excluyente.

Centrándonos en el tema de las religiones, en las sociedades contemporáneas altamente secularizadas el modelo de animosidad excluyente propio de las religiones ${ }^{2}$ se ha ido deslizando hacia uno de rivalidad cada vez con más elementos compatibilistas. Así, una persona abierta y tolerante, aunque sea miembro de una determinada confesión religiosa, podría estar dispuesta a colaborar en proyectos conjuntos (sociales, humanitarios o educativos) con miembros de otras confesiones, e incluso quizá a participar ocasionalmente en sus actividades y ceremonias -máxime si se trata de confesiones pertenecientes a una misma gran tradición, como, por ejemplo, en las diferentes iglesias dentro de la tradición cristiana-. El problema es que esta actitud ecuménica aperturista genera importantes tensiones, sin duda tanto mayores cuanto más diferentes sean las confesiones religiosas en diálogo ${ }^{3}$.

Antes de seguir avanzando, tenemos que especificar nuestra noción de secularización. Según Charles Taylor ${ }^{4}$, hay tres sentidos del término "secularización": a) una separación de los ámbitos religioso y civil dentro de la sociedad, desligándose las instituciones civiles de las religiosas (p. e. las universidades públicas de las eclesiásticas) y singularmente estableciendo una separación entre Iglesia y Estado. De este modo, las instituciones y estamentos civiles, así como sus actividades y prácticas, ya no se rigen por la religión. b) La creencia tradicional en Dios (o las divinidades, o

\footnotetext{
${ }^{1}$ Naturalmente, las religiones y sus profetas han competido a menudo entre sí, pero, a diferencia de las competiciones deportivas, no se trata de un enfrentamiento cada cierto tiempo o periódicamente establecido, donde lo relevante es acumular triunfos; es una batalla de aniquilación. Así, en 1Re 18:21 y ss. se relata que, en una contienda pactada, los 450 profetas de Baal invocaron los primeros a su dios, aunque infructuosamente, mientras que a continuación Yahvé sí atendió la invocación de Elías: “su fuego devoró el holocausto y la leña", demostrando ser el Dios verdadero, tras lo cual todos los pseudo-profetas de Baal fueron degollados. Un equipo que pierde a menudo es un mal equipo, pero un profeta que falla es simplemente un falso profeta.

$2 \mathrm{O}$ al menos de la mayoría de ellas, especialmente en el caso de las monoteístas.

3 Ya hace tiempo seńalaba Raimon Panikkar que el camino hacia el ecumenismo es largo y progresivo. Concretamente señalaba seis fases: coexistencia, tolerancia, diálogo, comprensión mutua, comunicación y, finalmente comunión (Religión y religiones Madrid, Gredos, 1965; p. 14). Obviamente, las subsiguientes al diálogo son cada vez más difíciles, como lo muestra la imposibilidad, hasta hoy, de lograr la comunión entre las iglesias cristianas, cuyo número y diversidad no ha cesado de crecer en los últimos dos siglos.

4 Taylor, Ch., A Secular Age, Cambridge, Mass., Harvard Uni. Press, 2007, pp. 1-3. He intercambiado el orden de los puntos dos y tres tal y como aparecen en Taylor, pues me parece que es el carácter cuestionable de la creencia en Dios lo que propicia -al menos parcialmente- la disminución de las creencias y prácticas religiosas, y no al revés, ni tampoco que sean aspectos independientes.
} 
los seres sobrenaturales) ya no es incuestionada, sino una opción abierta entre otras, como el deísmo, el agnosticismo o el ateísmo. Y c) una disminución patente de las creencias y las prácticas religiosas.

Taylor, sin embargo, pretende desacreditar la tesis habitual de la influencia del desarrollo científico en la disminución de las creencias religiosas, alegando: "no veo la contundencia de los supuestos argumentos a partir de, digamos, los descubrimientos de Darwin hacia la pretendida refutación de la religión" 5 . Dejando de lado que las dificultades para las creencias religiosas (especialmente las monoteístas) proceden no solo de la biología, es destacable que esa misma incapacidad para ver contradicción entre darwinismo y religión se daba ya en la época de Darwin en algunas mentes abiertas e ilustradas. En una carta de 1866, Mrs. Boole interpela a Darwin:

¿Considera vd. que sostener su teoría de la selección natural, en su sentido más pleno e irrestricto [o sea, incluyendo al hombre] es inconsistente -no digo con algún esquema particular de doctrina teológica- con la siguiente creencia, a saber: Que el conocimiento es dado al hombre por la inspiración directa del Espíritu de Dios, que Dios es un ser personal e infinitamente bueno... Mi propia impresión ha sido siempre... que su teoría era perfectamente Compatible con la fe a la cual acabo de intentar dar expresión. [cursivas mías]

\section{Darwin responde:}

Habría quedado sumamente gratificado si pudiera haberle enviado a usted respuestas satisfactorias a sus preguntas, o, en verdad, respuestas de cualquier tipo. Pero no puedo ver cómo la creencia en que todos los seres orgánicos, incluyendo al hombre, han sido derivados genéticamente de algún ser simple, en lugar de haber sido creados por separado, afecta a sus dificultades... No obstante, señalo que siempre me ha parecido más satisfactorio mirar a la inmensa cantidad de dolor y sufrimiento en este mundo como el resultado inevitable de la secuencia natural de sucesos, i.e. leyes generales, más bien que de la intervención directa de Dios ${ }^{6}$

En suma, en medio de una agria e intensa polémica por parte de varios teólogos cristianos contra Darwin y sus defensores, Mrs. Boole afirma no ver incompatibilidad entre evolucionismo darwinista y teísmo. Darwin conviene en ello, aunque dice no considerarse capacitado para juzgar al respecto. Pero, a su vez, afirma que sí detecta incompatibilidad entre la intervención divina (la Providencia) y el hecho del mal. Entonces, el evolucionismo completo (hombre incluido) sería incompatible con el Génesis (desde luego con su interpretación literal, como ocurre en muchas de las confesiones protestantes, aunque no solo en ellas) si bien no con el teísmo.

\footnotetext{
5 Ibid. p. 4.

${ }^{6}$ Darwin, Ch., The life and Letters of Charles Darwin, Vol II, Gloucester, Dodo Press, 2011, pp. 289-291.
} 
Lo incompatible con el teísmo, para Darwin, sería el hecho y alcance del dolor y el sufrimiento. Pero la cuestión es que las religiones monoteístas que de facto se practican son judaísmo, cristianismo e islam, todas ellas comprometidas con el Génesis, mientras que el teísmo es una posición filosófica, no una religión positiva. Por eso la creencia religiosa en general, incluso la teísta, puede sobrevivir a Darwin, pero la práctica de las religiones monoteístas establecidas (y ese y no otro es el aspecto (c) de la secularización que aquí nos ocupa) sí se resiente, porque se ven directamente afectadas las creencias específicamente judeo-cristianas sobre el origen del hombre ${ }^{7}$.

Volviendo ahora a la clasificación de Taylor ${ }^{8}$, podríamos debatir si se trata de tres significados distintos de "secularización" o más bien de tres aspectos o niveles, relativamente independientes a la vez que complementarios, que por lo general se van acumulando cuanto más secularizado está un país -como efectivamente tiendo a pensar-. Esto lo visualizaremos mejor si aludimos a casos concretos. Por ejemplo, si pensamos en Arabia Saudita, no se da allí ninguno de los tres niveles. Sería el grado cero de secularización. Si ahora miramos hacia a la India, estaríamos en el primer nivel: se da allí una separación legal entre el Estado y las confesiones religiosas, pero la creencia en Dios o en los dioses no es cuestionada, y las creencias y prácticas religiosas son muy mayoritarias. Se entiende y asume la diversidad de creencias y prácticas religiosas: uno puede ser visnuita, shivaíta, shaktista, musulmán, cristiano o incluso budista, pero se presupone que pertenecerá a una u otra tradición religiosa. Es el nivel uno de secularización.

Ahora trasladémonos a los EE.UU. -sin olvidar que EE.UU. es un país muy variopinto, con diferencias enormes entre ciudades como Nueva York o San Francisco y las zonas rurales del medio Oeste o del Sur-. Además de la separación constitucional entre el Estado y las confesiones religiosas, la creencia en Dios o en lo sobrenatural ya no es tan incuestionada, sino una opción (opción, por cierto, quizá minoritaria en ámbitos intelectuales y académicos, pero bastante mayoritaria entre la población en general, máxime en el ámbito rural). Esto hace que las creencias y

\footnotetext{
Prácticamente todos los mitos cosmogónicos fundacionales de las religiones relatan dos (o en su caso, tres) aspectos esenciales: a) el origen del universo, b) el origen de los dioses (en las tradiciones politeístas), y c) el origen de la humanidad. Este último nunca falta, y es esencial para explicar (de maneras muy diversas, por cierto) el origen y sentido del sufrimiento y el dolor, y, en consecuencia, el sentido último de la existencia humana.

${ }^{8}$ La clasificación de Taylor no es idéntica a la previa de José Casanova. Casanova distinguía también tres sentidos de "secularización", los dos primeros que Taylor recoge junto con el de la retracción de la religión a la esfera privada desapareciendo de la pública (en lugar de la cuestionabilidad de la creencia en Dios, de Taylor). Cf. Casanova, J., Public Religions in the Modern World, Chicago, University of Chicago Press, 1994, p. 19 y ss. Y asimismo "Rethinking Secularization: A Global Comparative Perspective", en The Hedgehog Review / Spring \& Summer, 2006, p. 7-8 (traducido e incluido en su libro Genealogías de la secularización, Barcelona, Anthropos, 2013, p. 33-34.). Las diferencias en la clasificación muestran que a Casanova le interesa el rol social e histórico de la religión, mientras que Taylor incide en las cuestiones epistémicas que atañen a las creencias religiosas.
} 
(en menor medida) las prácticas religiosas en EE.UU. preponderen considerablemente sobre su ausencia ${ }^{9}$. Estamos en el nivel dos de secularización.

Finalmente tenemos aquellos países (como Japón, Alemania o Canadá) en los que, además de la separación entre el Estado y las confesiones religiosas, y del carácter opcional de las creencias religiosas, la práctica de las religiones ha descendido llegando a resultar claramente minoritaria. Aquí se da el nivel tres de secularización.

Pues bien, una cuestión tan relevante como debatida es la causa (o causas) de esta secularización, que no es exactamente igual en sus distintos niveles. El nivel o sentido (a), la separación entre las instituciones religiosas y las civiles (o, para ser más exactos, la emancipación de la sociedad civil y sus instituciones del poder e influencia de las entidades religiosas) tiene mucho más que ver con la historia de cada país, con sus luchas de poder y con cuestiones políticas. Así, el Reino Unido, un país fuertemente secularizado en los niveles (b) y (c), no lo está en el nivel (a), pues el Estado es oficialmente anglicano, y la Reina cabeza a la vez del Estado y de la Iglesia. Lo cual, obviamente, solo se explica por la "peculiar" historia personal de Enrique VIII y de los subsiguientes enfrentamientos de Inglaterra con el papado romano y con los Reinos católicos de Europa.

Centrémonos ahora en los aspectos (b) y (c), que en mi opinión se hallan estrechamente relacionados. EE.UU. suele citarse como el contraejemplo a la ecuación de que desarrollo científico y cultural implica disminución de las creencias y prácticas religiosas. También sería, supuestamente, uno de los pocos casos en que se da el nivel (b) de secularización, pero no el (c). Esto, sin embargo, debe analizarse con cuidado. En cuanto al nivel (b), me parece bastante cuestionable hasta qué punto es de veras una opción real e inocua a nivel social el ateísmo (recordemos que a Barack Obama se le recriminó por haber comenzado a ir a misa semanas antes de las elecciones, cuando habitualmente no asistía). Por lo que respecta al nivel (c), también resulta discutible hasta qué punto la práctica de la religión esté tan arraigada como pueda parecer a primera vista (como acabo de señalar en una nota, menos de la mitad de los que se autocalifican como cristianos acude a la iglesia con regularidad). Las estadísticas también muestran que en varios ámbitos urbanos de EE.UU. se dan bastante estos dos últimos niveles de secularización, mientras que

\footnotetext{
9 Según la organización Pewforum, en 2014 el 70\% de los estadounidenses se declaran cristianos, el 6\% seguidores de otras religiones, y solo el $23 \%$ como no religiosos. Las diferencias por estados son relativamente significativas. Por ejemplo, los cristianos van desde el 86\% de Alabama hasta el 54\% de Vermont. Algo más importantes son las diferencias en cuanto al nivel de estudios, mientras que el 33,4\% de la población adulta de EE.UU. tiene una licenciatura o grado universitario, solo tiene tal nivel de estudios el $25 \%$ de los cristianos. Pero aún más relevantes son las diferencias entre las creencias y la práctica: mientras que el $94 \%$ de los cristianos afirman creer con certeza (76\%) o casi (18\%) en Dios, la religión es muy importante en su vida solo para el $68 \%$, y van a misa semanalmente únicamente el $47 \%$ (fuente, Pewforum org. http://www.pewforum.org/religious-landscape-study/) [consultado 8/3/2018].
} 
en los rurales ambos niveles se hallan mucho más reducidos. Así, mientras que la media de personas no religiosas del país es el 23\%, en Boston, San Francisco y Seattle lo son respectivamente el 33,35 y $37 \%{ }^{10}$. Esto podría ser indicativo de una importante correlación entre los niveles de secularización (b) y (c); al fin y al cabo, resulta lógico que cuando la creencia en Dios se vuelve opcional, también se vean disminuidas las demás creencias religiosas y, correlativamente, las prácticas religiosas.

Al menos desde Auguste Comte tenemos la afirmación de que la Ilustración y la ciencia acabarán desplazando a la religión, y son muchos los críticos de la religión que la rechazan por razones epistémicas desde al ámbito científico ${ }^{11}$. Así, los países más ilustrados habrían de ser los más secularizados en los tres niveles. Sin embargo, acabamos de concluir que EE.UU., sin duda el mayor productor de ciencia del mundo, está bastante poco secularizado en el nivel tercero. Pero, volvemos a cuestionarnos, ¿es en verdad EE.UU. un contraejemplo a esta tesis cientificista y positivista? Hace ya más de un siglo que William James en Harvard se quejaba de que, entre sus colegas de universidad, estaba mal visto el ser religioso, y que por lo general se consideraba a la religión (es decir, al cristianismo) como una suerte de reliquia supersticiosa propia del pasado. Y esta tendencia no ha hecho sino acentuarse en el siglo transcurrido. El problema es que la influencia de la ciencia -y de las disciplinas académicas universitarias en general- en la población del norteamericano medio es harto reducida, porque existe un verdadero hiato entre las élites intelectuales y académicas de los EE.UU. y el resto de la población. Eso, al menos en parte, es lo que explicaría que la potencia científica del país no haya acarreado una disminución importante de las prácticas religiosas entre la población en general, que sencillamente ignora tanto los avances científicos como la propia actitud y

\footnotetext{
${ }^{10}$ http://www.pewresearch.org/fact-tank/2015/07/29/major-u-s-metropolitan-areas-differ-in-their-religious-profiles/. No obstante, es justo reconocer que en otras metrópolis, como Nueva York, Los Ángeles o Chicago, el índice de no afiliación religiosa prácticamente coincide con el global del país, si bien el número de cristianos (especialmente protestantes) es significativamente menor, a cambio de una mayor proporción de devotos de otras religiones.

11 Por lo general, muchos científicos se desinteresan por la religión, o la consideran un asunto privado, pero algunos son antagonistas muy activos. Un ejemplo es el premio Nobel Francis Crick: "No me cabe duda... de que esta pérdida de fe en la religión cristiana y mi creciente apego a la ciencia han desempeńado una parte dominante en mi carrera científica... pronto caí en la cuenta de que es el conocimiento científico detallado lo que hace insostenibles ciertas creencias religiosas." (What Mad Pursuit: A Personal View of Scientific Discovery, Basic Books, Nueva York, 1990, p. 11). Crick ve el conflicto específicamente entre el cristianismo -sobre todo los asertos bíblicos acerca del origen del hombre, de la vida y de la Tierra- y los descubrimientos científicos, y critica la presencia e influencia de la Iglesia en los ámbitos académicos, incluidos los universitarios. Concuerda con Richard Dawkins, el apóstol del ateísmo en Gran Bretaña, quien en su libro The God Delusion (Houghton Mifflin Company, Boston, 2006) ha criticado tanto la inconsistencia de la creencia en Dios ante el estado actual de los conocimientos científicos (cap. 4) como la influencia social de las iglesias y la educación y la moral religiosas (caps. 8-9). Probablemente el científico más notorio que se ha pronunciado, no ya contra la Iglesia o la religión cristiana, sino directamente contra la creencia en Dios, es el recién fallecido Stephen Hawking.
} 
metodología de la ciencia, cuando no simplemente desprecia todo lo que proceda de los intelectuales ${ }^{12}$.

De hecho, el mayor punto de conflicto en EE.UU. entre la religión y la ciencia ha sido siempre por el tema del evolucionismo. Dejaremos de lado la cuestión de si el evolucionismo es o no efectivamente incompatible con la Biblia, o solo lo es con una lectura fundamentalista y literalista de la misma. El hecho es que para muchos norteamericanos, protestantes en su mayoría, se da tal incompatibilidad ${ }^{13}$. Y forzados a tener que elegir, esos cristianos optan, naturalmente, por la versión bíblica. En suma, si EE.UU. está poco secularizado en cuanto a las creencias y prácticas religiosas, ello, pace Taylor y otros, podría deberse en parte al escaso nivel cultural de buena parte de su población. El país es la mayor potencia científica, pero eso permea tan poco hacia las clases menos favorecidas como escasamente fluye su potencia económica, medida por el PIB o la renta per cápita, hacia las enormes bolsas de población que vive con los recursos justos o bajo el umbral de la pobreza.

Otra razón, muy distinta de la anterior, aducida para explicar la secularización, o más específicamente su nivel (c), en los países donde acaece, es la dificultad de la experiencia religiosa en las sociedades urbanas modernas. En las grandes metrópolis el ajetreo, el estrés, las continuas prisas, el bullicio permanente, no constituirían un locus adecuado para la experiencia religiosa, y con ello para la práctica de la religión.

De nuevo, esto puede ser parcialmente cierto, y ser parte de la explicación del por qué en los ámbitos rurales la religión se practica casi siempre más que en los urbanos. Pero acaso solo parcialmente. Es explicativo en cuanto a la escasez de tiempo, que hace que sea más arduo encontrar el momento para las actividades religiosas, más allá de una escueta ceremonia dominical (o del día correspondiente de la semana). Pero no lo es tanto en cuanto al tipo de experiencia. Porque tal explicación sí valdría para la experiencia religiosa de aislamiento y recogimiento (factible en el ámbito rural y casi inviable en el urbano), pero no para la experiencia comunitaria multitudinaria, especialmente la de tipo "pentecostal". Precisamente las grandes ceremonias religiosas de exaltación tienen lugar en grandes habitáculos o espacios propios de las zonas urbanas: templos enormes o canchas deportivas utilizadas para ceremonias religiosas, donde cientos o miles de enfervorizados devotos dan rienda suelta a su frenesí. Por ello, el hecho de la preponderancia de la práctica religiosa en el medio rural seguramente tiene más que ver

\footnotetext{
${ }_{12}$ Que un sujeto como Donald Trump haya podido ser elegido presidente del país (aunque fuera con menos del $50 \%$ de los votos efectivos) es un síntoma del nivel cultural y educativo de la población en general.

${ }^{13}$ No tanto en cuanto al evolucionismo como teoría biológica de evolución de las especies, sino en cuanto al caso específico del hombre como un producto más de la evolución. Un evolucionismo como el de Wallace, que excluye al hombre del proceso evolutivo, no causaría problemas.
} 
con la circunstancia de que allí se está mucho más apegado a las tradiciones y menos influido por las innovaciones culturales e ideológicas, a menudo distantes o incluso hostiles con la religión ${ }^{14}$. Y la religión es y ha sido siempre un aspecto esencial de la tradición de un pueblo.

Una razón más para la secularización, y esta es la que singularmente me interesa aquí, puede ser la toma de conciencia de la diversidad y del carácter problemático de las tradiciones, experiencias, prácticas y creencias religiosas ${ }^{15}$. Esto se da no solamente en el ámbito urbano con preferencia al rural, sino especialmente en las metrópolis muy cosmopolitas, con porcentajes de inmigración tan numerosos como diversos (Nueva York, Londres, San Francisco etc.). El cosmopolitismo de estas urbes nos hace conscientes de la sociedad global y coadyuva al pluralismo cultural y social, y en particular al religioso.

Aspecto correlativo y complementario de esta interrelación socio-cultural, es el deseo de conocimiento de la diversidad de las religiones: la curiosidad por lo exótico, por lo distinto, por lo alternativo. Curiosidad que impulsa y retroalimenta ese fenómeno desbocado de masas que es el turismo, y también los actuales medios de difusión (documentales, vídeos, blogs, redes sociales, etc.).

La diversidad de opciones en todos los ámbitos es un rasgo distintivo en las sociedades cosmopolitas capitalistas avanzadas. Esta diversificación opcional, como ya indiqué al inicio, puede ser de tres tipos. Es compatibilista o complementaria, cuando podemos optar por varias opciones a la vez ${ }^{16}$. El ideal es que uno conozca $y$ pruebe de todo, y luego elija (en plural) todo aquello que le guste. Las sociedades cosmopolitas e informadas convierten cualquier producto en una dualidad: económica (negocio) para el productor/vendedor y estética o de fruición para el consumidor. Los eslóganes favoritos de la publicidad son del tipo: "no te puedes perder...", "ite vas a quedar sin probar...?" o similares. El modelo compatibilista fomenta, pues, la diversificación y con ello hace aumentar el "consumo global" de los productos en oferta en un ámbito determinado.

Cuando la opcionalidad comporta una rivalidad inclusiva, elegir una opción significa descartar (al menos durante un tiempo) las demás alternativas (como ocurre

\footnotetext{
${ }_{14}$ Singularmente cuestiones morales contrarias a la ética religiosa tradicional, tales como el matrimonio homosexual, la permisión del aborto, el divorcio, la eutanasia, la eugenesia y manipulación genética, etc.

15 Es difícil cuantificar la influencia de este aspecto, y probablemente no sea la razón más importante de la secularización -especialmente de su nivel (c)-, pero considero que es un factor bastante relevante, y que, lentamente, ha ido permeando en las capas de la población de gran parte de las sociedades contemporáneas occidentalizadas.

${ }^{16}$ Por ejemplo, en el caso de los alimentos, la diversidad y la curiosidad han aumentado exponencialmente. Hasta no hace mucho uno iba a comprar arroz, sal o tomates. Ahora hay una decena de tipos de arroces, tantas o más de sales, y no digamos de tomates (que además podemos comprar en cualquier época del año). Y otro tanto ocurre con la mayoría de los alimentos.
} 
con los productos electrónicos o con los clubes deportivos ${ }^{17}$ ) pero a la vez que las demás sigan existiendo como rivales con los que competir.

Por último, cuando la opcionalidad implica una animosidad excluyente las alternativas rivales se convierten en antagonistas cuya mera existencia desafía a la posición propia. Pues bien, las "ofertas" religiosas tradicionalmente se ubicarían en este tercer modelo de las ofertas alternativas, excluyentes, combativas, pues las confesiones religiosas exigen fidelidad y exclusividad ${ }^{18}$. Y ello por dos buenas razones. Epistémicamente, pues cada una afirma poseer la verdad última (su particular credo). Soteriológicamente, pues cada una afirma ser la vía exclusiva de salvación (extra ecclesiam nulla salus). Se trata de ofertas de sentido que rivalizan sin cuartel entre sí. Este elemento salvífico, y, sobre todo, el epistémico es lo que diferencia a las ofertas religiosas de las deportivas. La verdad exige unicidad. La vía hacia la salvación suele exigirla. La pasión, la emoción o el gozo, no. "Ojalá un día solo exista mi religión" puede pensar y desear un musulmán, un cristiano o un judío. "Ojalá solo existiera mi equipo" es un pensamiento sin sentido para cualquier practicante profesional o forofo de cualquier club deportivo.

No obstante, el hecho cada vez más presente y palmario de la pluralidad de religiones exige (para las personas con actitudes, creencias y sentimientos religiosos) una profunda reflexión y un posicionamiento más autocrítico. Y el siglo XX ha visto cómo, dentro de la teología cristiana, se tematizaban las posibles respuestas. En primer lugar, mantenerse firmes en la posición tradicional: mi religión -en este caso la cristiana- es la única verdadera, la única vía de salvación, porque Dios se ha hecho hombre para redimir a la humanidad únicamente una vez y en Cristo Jesús. Es la propuesta que John Hick denomina exclusivismo ${ }^{19}$.

El exclusivismo es lo que hoy día resulta muy difícil de sostener para un europeo ilustrado, porque somos conscientes de la historicidad de las religiones, de lo aleato-

\footnotetext{
${ }^{17}$ Así, por ejemplo, cuando me compro un teléfono móvil elijo una marca y modelo concreto, descartando los demás (como cuando elijo trabajar con un sistema operativo en el ordenador). O cuando, como aficionado a un deporte determinado, me hago socio de un club, descartando los demás (uno puede, teóricamente, ser socio del Real Madrid y del Atlético, pero desde el punto de vista del forofo no tiene ningún sentido, por mucho que le guste el fútbol). Pero es esencial que haya en el mercado varios modelos de móvil para comparar y elegir, y aún más que haya varios clubes de fútbol competitivos para que pueda establecerse una liga o un campeonato realmente interesante.

${ }^{18}$ El concepto de Yihad en el islam significa la Guerra Santa contra cualquier grupo ideológico/religioso que suponga una amenaza para la supervivencia del islam. En teoría se trata de una doctrina de legítima defensa. Pero el problema es que la mera existencia de ofertas de sentido alternativas ya constituye en sí misma una amenaza, pues puede "robar" adeptos del islam hacia otras religiones.

19 John Hick: "Hacia una comprensión religiosa de la religión”, en J. Gómez Caffarena y J.M. Mardones (eds.): Estudiar la religión. Barcelona, Anthropos, 1993; p 99-100. Hick atribuye esta postura al teólogo luterano Karl Barh, cuya Kirchliche Dogmatik es la obra cumbre de la teología dogmática ortodoxa luterana del siglo XX. No obstante, hay cierta controversia acerca de si Barth fue tan "exclusivista" como piensan sus críticos. En todo caso, la idea de que todas las religiones salvo la propia son meras proyecciones de la imaginación humana le parece a Hick inaceptable por arbitraria.
} 
rio de haber nacido en un lugar y época determinados, y, en consecuencia, de haber sido criados dentro de una tradición religiosa más bien que dentro de otra. Sería sumamente injusto que alguien fuera excluido de la posibilidad de salvación por el mero hecho de haber nacido en el tiempo y lugar "inadecuados".

Para dar respuesta a esta inquietud, el Concilio Vaticano II, apoyado por jóvenes teólogos, ofreció la solución: si bien mi religión es la óptima, las demás son también experiencias genuinas de la divinidad o Realidad Última y, por ende, vías auténticas de realización espiritual e incluso de salvación. Es lo que se ha denominado inclusi$v i s m o^{20}$, postura que resulta mucho más razonable para un europeo ilustrado contemporáneo. Sin embargo, no se trata de algo totalmente novedoso en la tradición judeo-cristiana. Así, en el Zohar se afirma: Israel.

El grado de esencia divina que designa este nombre, $\mathrm{YHVH}$, fue revelado únicamente a

Pero otro grado de esencia divina se ha manifestado aquí abajo con diferentes formas. Cada uno de los nombres divinos designa distintos veres y sentires. Esta gradación es conocida por el nombre general de Elohim. Todos los pueblos del mundo, incluso aquellos que adoran los cuerpos celestes a los que el Santo, bendito sea, ha dado poder de gobierno sobre las naciones, e incluso los pueblos idólatras han conocido con cualquier nombre este grado de esencia divina que designa el nombre de Elohim.

Así, dicen las Sagradas Escrituras: Elohim se le apareció por la noche a Balaam. (Num. 22:20), y: Elohim se Ie apareció en sueños a Abimelec. (Gen. 20:3) 43. También todos los gobernantes (dioses) que Dios ha dado a otras naciones son conocidos por el mismo nombre. La idolatría misma es llamada Elohim. Este es el nombre conocido por las naciones, pero a lsrael, Su único pueblo, Su pueblo santo, le ha revelado el nombre de YHWH. ${ }^{21}$

Lo interesante es que el Zohar (que en realidad es del siglo XIII) se pensó siempre que era de inicios de nuestra era (del Rabbí Simeón bar Yohai), con lo que el inclusivismo habría sido reivindicado desde muy antiguo. Pues bien, el inclusivismo tiene dos ventajas: 1) nos permite (a los europeos religiosos) seguir practicando nuestra religión cristiana (tomar en serio la religión). 2) Nos obliga a ser no solo tolerantes, sino respetuosos con las demás religiones (apreciar la diversidad de opciones de creencia). Más aún, diría que nos invita a ser receptivos ante las demás confesiones religiosas.

Sin embargo, el conocimiento detallado de las diversas religiones (incluida la nuestra) y de su historia (algo cada vez más frecuente en Europa) nos induce a preguntarnos: ¿por qué ser inclusivista desde mi religión más bien que desde otra?

\footnotetext{
${ }^{20}$ El gran defensor de esta tesis fue el teólogo católico Karl Rahner.

${ }^{21}$ Zohar: el libro del esplendor (selección), tr. Carlos Giol, Barcelona, Obelisco, 2012, p. 60-61.
} 
$\mathrm{Y}$, si ninguna se nos aparece como claramente superior, entonces nos vemos abocados a dar un paso más, desembocando en el pluralismo. Es la postura uno de cuyos máximo exponentes ha sido John Hick ${ }^{22}$. Para él, todas las grandes religiones son respuestas genuinas ante una Realidad Última única, de cuya experiencia todas participan en diversos grados y maneras, no siendo ninguna de ellas la óptima, ni siquiera claramente superior a las demás. Pero coincidiendo todas en lo fundamental, que para Hick no son los asertos metafísico-teológicos, sino las prescripciones morales fundamentales, los mandamientos y, en última instancia, la regla de oro: no quieras para los demás lo que no quieres para ti, que aparece fundacionalmente en todas ellas. En definitiva, un alegato en contra del egoísmo y a favor del altruismo ${ }^{23}$.

Pues bien, a todas estas consideraciones en favor del pluralismo desde los ámbitos de la teología y de la filosofía de la religión, que resultan ser convergentes, se han unido otras tantas desde las esferas de la sociología y de la filosofía política. De este modo, desde "La religión en la esfera pública" ${ }^{44}$ (aparecido en 2005) Jürgen Habermas ha señalado que el creyente actual, para poder participar en pie de igualdad en los debates de la sociedad civil, debe hacer una autorreflexión que le lleve a reconocer el hecho del pluralismo religioso, y a renunciar a cualquier forma de fundamentalismo o exclusivismo, a cualquier intento de monopolizar la verdad. Y asimismo reconocer la preeminencia política del derecho racional y de la moral universalista.

En una línea semejante, Jean Marc Ferry ha señalado que las religiones deben adoptar una actitud falibilista en materia de sus tesis y propuestas religiosas. No puede adoptar, en el espacio público, la forma autoritaria e incuestionable de tiempos pasados:

${ }^{22}$ Loc. cit. p. 101 y ss. Una crítica de la postura de Hick puede verse en E. Romerales, "El pluralismo religioso de John Hick" (ibídem pp. 287-304). La defensa más detallada de la postura pluralista de Hick a favor de la religión la desarrolló en su libro An Interpretation of Religion (Londres, Macmillan, 1989, esp. caps. 14-16).

${ }^{23}$ Sarvepali Radhakrishnan (La concepción hindú de la vida, Madrid, Alianza, 1969) nos recuerda el relato hindú según el cual un grupo de ciegos se topó con un elefante cuando los llevaban de paseo, cada uno palpó una parte diferente del paquidermo, y al volver a casa relataron experiencias muy diversas del animal. Todas eran ciertas, pero también sesgadas; ninguna era más auténtica que las demás. Así, el autor afirma: "el pensador hindú está dispuesto a admitir rápidamente puntos de vista diferentes del suyo y los considera tan merecedores de atención como el propio" (p. 21) ... La caza de herejías, deporte favorito de numerosas religiones, está singularmente ausente en el hinduismo" (p. 45) ... No es justo ni hacia Dios ni hacia el hombre el suponer que exista un pueblo elegido por Dios, que su religión ocupe un lugar central en el desarrollo religioso de la humanidad y que todas las demás deban imitarla o sufrir una destitución espiritual... La religión no es una creencia correcta, sino una vida recta" (p. 61). No está de más recordar que Radhakrishnan, además de reputado filósofo (que fue profesor de religiones orientales en Oxford) y persona de reconocida espiritualidad, fue primero vice-presidente y luego presidente de la India entre 1952 y 1967.

${ }^{24}$ Habermas, J, "Religion in der Öffentlichkeit”, en Zwischen Naturalismus und Religion. Philosophische Aufsätze. Frankfurt am Main, Suhrkamp, 2005, pp. 119-154. 
«Dios dice que...» ha dejado de ser un argumento admisible, menos aún un argumento dirimente, en nuestros espacios cívicos. Aunque una sociedad verdaderamente liberal tolera la expresión pública de todas las opiniones y convicciones, solamente algunas de ellas, las que concuerdan con la gramática del derecho moderno, pueden ofrecer una base aceptable para las deliberaciones políticas ${ }^{25}$.

Visto desde la sociedad civil, desde el Derecho y desde el sentido común, el pluralismo tiene ciertamente muchas ventajas. Sin embargo, también acarrea serios inconvenientes. A nivel teórico, el principal: la verdad es una, y las diversas religiones representan ofertas epistémicas no solo diferentes, sino en muchos respectos incompatibles. Esta incompatibilidad afecta incluso al núcleo de aserciones metafísicas base acerca de la Realidad Suprema. Y este es un escollo que parece insuperable ${ }^{26}$. A nivel práctico, devocional, el problema aparece como más acuciante, si cabe. Porque la religión es algo que se profesa, se vive, permeando la actividad completa de la persona. Y eso no es nada fácil conjugarlo en modo plural. La cuestión es: ¿qué religión practicará un pluralista? ¿Varias? De ser varias, ¿cómo?: ¿̨alternativamente?, ¿ocasionalmente? Y si, en cambio, solo practica la suya, el dilema será optar entre no tomar su religión con la exigencia de seriedad e incondicionalidad que (¿casi?) toda religión exige a sus devotos, o, de lo contrario, diluir su pluralismo hasta dejarlo en algo nominal más que real. Esa, y no otra, es la cuestión crucial: si un verdadero judío, cristiano, musulmán, mormón (o incluso hinduista, budista o taoísta) puede ser simultáneamente un genuino pluralista ${ }^{27}$.

A mi parecer, el pluralismo, tomado como opción vital personal, más bien conduce a una actitud religiosa genérica naturalista o cósmica, pero sin un compromiso

${ }^{25}$ Ferry, J. M., "La religión in foro publico", en Romerales, E., y Zazo, E. (eds.), Religiones en el espacio público, Barcelona, Gedisa, 2016, p. 29. Ferry desarrolla in extenso su postura en su libro Les Lumières de la religion. Les religions dans l'espace public, Bayard, 2013, (esp. caps. 1-2).

${ }^{26}$ Los intentos de superarlo aludiendo a la semejanza o incluso uniformidad de las experiencias místicas en las diversas tradiciones histórico-culturales han sido duramente criticados, entre otros, por Stephen Katz en su artículo "Language, Epistemology and Mysticism" (en S. T. Katz (ed.): Mysticism and Philosophical Analysis, Londres, Sheldon, 1978; pp. 22-66). Esencialmente el argumento de Katz es que las experiencias místicas de referentes como la Trinidad, Alá, Brahman o el Nirvana son tipos de experiencias distintas e irreductibles, y si las experiencias místicas más radicales a veces se parecen es únicamente porque se vacían de todo contenido. Al insistirse en su carácter paradójico e inefabilidad, se corre un velo sobre las mismas que hace imposible saber qué hay detrás ni, en consecuencia, si el referente de las diversas experiencias "inefables" es o no el mismo (ídem. p. 40).

${ }^{27}$ Es probable que esto resulte mucho más difícil en las religiones monoteístas, cuyos dioses son celosos (recordemos que el primer mandamiento del Decálogo es no tener a otro dios que a Yaveh). En las henoteístas y politeístas con frecuencia el mismo culto permite la pluralidad devocional. Como ejemplo podemos citar el famoso templo taoísta de Lung-Shan de Taipei, donde, si bien preside el Emperador de Jade (divinidad suprema taoísta) y las divinidades taoístas son mayoritarias, en lugares prominentes figuran boddhisattvas budistas como Avalokiteshvara, Manńjusri o Samantabhadra, o divinidades hinduistas como Skanda, y así hasta un total de 166 divinidades, recibiendo todas culto y ofrendas (Hsiao-Lan, Hu \& Allen, William: Taoism, Langhorne, PA, Chelsea House Publishers, 2005; pp. 34-37). 
efectivo con ninguna religión positiva (por compromiso efectivo entiendo no solo el participar con determinada frecuencia de ciertas ceremonias religiosas, sino el estar dispuesto a cumplir los preceptos de una religión, e incluso a ser un apóstol de esa religión). La apuesta seria por el pluralismo religioso conduce bien a una religiosidad natural (deísmo o teísmo filosófico), bien quizá a un agnosticismo; positivo, como el de Anthony Kenny ${ }^{28}$, pero agnosticismo al fin y al cabo. Ambas actitudes desembocan en el progresivo abandono de la práctica regular y firme de cualquier religión positiva. Esto se muestra en el fenómeno sociológico extendido entre los occidentales, y especialmente los europeos, de la creencia sin pertenencia (Grace Davie ${ }^{29}$ ), o cristianismo difuso (Jeffrey $\mathrm{Cox}^{30}$ ). En suma, mientras que el inclusivismo se abre a la diversidad de las confesiones religiosas, el pluralismo acaba englobando la religiosidad difusa, o incluso la increencia, en dicha pluralidad.

Pues bien, las sociedades devocionalmente diversas, aquellas en las que existen como opciones vitales reales muchas y muy diversas opciones de sentido (agnosticismo y ateísmo incluidos), pueden no ser conflictivas si no hay pretensiones de imposición por ninguna de sus alternativas (Nueva York, caso paradigmático). El primer problema surge cuando alguna de las opciones religiosas se vive desde una ideología muy exclusivista (los mormones, p. e. con respecto a la poligamia, o los católicos, respecto a la prohibición del aborto). El segundo, cuando el exclusivismo religioso es fuertemente apostólico, proselitista (testigos de Jehová). El tercero, y mayor problema, surge cuando el exclusivismo, además de apostólico es beligerante (islam, en sus versiones más radicales, como la salafista). Cuando en una sociedad conviven dos o más opciones de creencia, y al menos una es exclusivista beligerante, pasamos del conflicto potencial al actual.

Si volvemos ahora nuestra mirada hacia Europa, por lo referente al cristianismo, en Europa tenemos sociedades con escasa pluralidad devocional en los países de tradición católica u ortodoxa, pero con una mayor pluralidad devocional en los países protestantes (diversidad que, no obstante, es incomparablemente menor que en los EE.UU.). Si añadimos el judaísmo y, sobre todo, el islam, la pluralidad devocional en suelo europeo aumenta significativamente (la presencia de otras religiones es, salvo excepciones, mucho menor). De hecho, el tercer apartado del artículo 17

\footnotetext{
${ }^{28}$ Anthony Kenny ha defendido un agnosticismo en el que la persona realmente duda de la existencia y, sobre todo, de la naturaleza de Dios, pero su conducta no implica desentenderse de la religión, sino abrirse a la religiosidad de un modo distinto, por ejemplo, rezando por si alguien "escucha al otro lado" o no descartando que ciertas afirmaciones sobre la divinidad puedan ser verdaderas en sentidos metafóricos (The Unknown God. Agnostic Essays, Nueva York, Continuum, 2004, caps. 3 y 7).

${ }^{29}$ Davie, G., Religion in Britain Since 1945: Believing Without Belonging, Blackwell, Oxford, 1994 y Religion in Modern Europe: A Memory Mutates, Oxford University Press, Oxford, 2000.

${ }^{30}$ Cox, J., The English Churches in a Secular Society, Nueva York, Oxford Uni. Press, 1982; cap. 4.
} 
del Tratado sobre el Funcionamiento de la Unión Europea estipula: «Reconociendo su identidad y su aportación específica, la Unión mantendrá un diálogo abierto, transparente y regular con las iglesias y organizaciones filosóficas no confesionales». Mayor aún es la diversidad de grados de asentimiento a las creencias y apego a las prácticas (desde las más practicantes Irlanda o Polonia hasta las muy poco practicantes como Gran Bretańa o Francia).

En suma, hay muchos países y regiones de Europa con una religiosidad difusa, con una creencia sin pertenencia. Esto es resultado de un largo proceso, con muchas causas (incluidas todas las arriba señaladas), pero pienso que una de ellas, y una cuya relevancia suele ser minusvalorada, es el conocimiento de, y la interacción con, las diversas religiones (sea por contacto histórico-geográfico, en las colonizaciones primero y con el turismo después, sea por la curiosidad y por el estudio). No olvidemos que fueron mayoritariamente europeos quienes iniciaron en el siglo XIX y desarrollaron ulteriormente los estudios críticos sobre hinduismo, budismo, judaísmo o islam... y muy especialmente cristianismo.

Si el estudio de otras religiones lleva a la tolerancia, al respeto, y a la duda sobre las creencias, el estudio de la religión propia (en el caso de los europeos, el cristianismo en sus diversas vertientes) hace el resto. Estudiar críticamente las religiones en pie de igualdad baja a la propia de su pedestal, siendo difícil que tal pedestal pueda volver a ser ocupado por cualquier otra.

A modo de conclusión, me atrevería a afirmar que la ilustración, el avance de los conocimientos científicos, tanto en las ciencias naturales como en las sociales, y muy especialmente en lo que se refiere a las religiones (la historia de las religiones y las ciencias de las religiones) han contribuido también a la secularización, seguramente no en su nivel (a), pero sí en el (b) y el (c). Esto a su vez ha propiciado, entre las personas religiosas más avanzadas, cultas y abiertas, una notable simpatía hacia el pluralismo religioso. Pero los "apóstoles" del pluralismo son con mucha mayor frecuencia intelectuales y académicos que autoridades de confesiones religiosas particulares con potestas en su organización.

Por su parte, la diversidad de confesiones religiosas (la pluralidad devocional), como un hecho incuestionable y creciente, no ya en lugares geográficamente distantes, sino in situ, ha alimentado también este pluralismo religioso. No obstante, el pluralismo religioso como actitud epistémica y, sobre todo, como opción vital, me parece una posición de suyo inestable, difícilmente sostenible a largo plazo. Y la paradoja es que la pluralidad devocional invita al pluralismo religioso, al menos en la medida en que un creyente quiera ser sensible a la alteridad, ser racional y estar informado en materia de religiones, como debería en la Europa del siglo XXI. 


\section{Referencias Bibliográficas}

Casanova, J., Public Religions in the Modern World, Chicago, University of Chicago Press, 1994.

Casanova, J., "Rethinking Secularization: A Global Comparative Perspective", The Hedgehog Review, Spring \& Summer, 2006.

Casanova, J., Genealogias de la secularización, Barcelona, Anthropos, 2013.

Cox, J., The English Churches in a Secular Society, Nueva York, Oxford Uni. Press, 1983.

Crick, F., What Mad Pursuit: A Personal View of Scientific Discovery, Nueva York, Basic Books, 1990.

Darwin, Ch., The life and Letters of Charles Darwin, Vol II, Gloucester, Dodo Press, 2011.

Davie, G., Religion in Britain Since 1945: Believing Without Belonging, Oxford, Blackwell, 1994.

Davie, G., Religion in Modern Europe: A Memory Mutates, Oxford, Oxford University Press, 2000.

Dawkins, R., The God Delusion, Boston, Houghton Mifflin Company, 2006.

Ferry, J. M., "La religión in foro publico", en Romerales, E., y Zazo, E. (2016; pp. 25-52).

Ferry, J.M., Les Lumières de la religion. Les religions dans l'espace public, París, Bayard, 2013.

Gómez Caffarena, J. y Mardones, J.M. (eds.), Estudiar la religión, Barcelona, Anthropos, 1993.

Habermas, J., Zwischen Naturalismus und Religion. Philosophische Aufsätze. Frankfurt am Main, Suhrkamp, 2005. Trad. esp. Entre naturalismo y religion, Barcelona, Paidós, 2006.

Habermas, J., "Religion in der Öffentlichkeit", en Zwischen Naturalismus und Religion (pp. 119-154).

Hick, J., An Interpretation of Religion, Londres, Macmillan, 1989.

Hick, J., "Hacia una comprensión religiosa de la religión”, en Gómez Caffarena, J., y Mardones, J. M. (1993; pp. 97-118). 
Hsiao-Lan, H. \& Allen, W., Taoism, Langhorne, PA, Chelsea House Publishers, 2005.

Katz, T. S. (ed.), Mysticism and Philosophical Analysis, Londres, Sheldon, 1978.

Katz, T. S., "Language, Epistemology and Mysticism", en Katz, S. T., (ed.), Mysticism and Philosophical Analysis; (pp. 22-66).

Kenny, A., The Unknown God. Agnostic Essays, Nueva York, Continuum, 2004.

Paniker, R., Religión y religiones, Madrid, Gredos, 1965.

Radhakrishnan, S., La concepción hindú de la vida, Madrid, Alianza, 1969.

Romerales, E., "El pluralismo religioso de John Hick", en Gómez Caffarena, J., y Mardones, J. M. (1993; pp. 287-304).

Romerales, E., y Zazo, E. (eds.), Religiones en el espacio público, Barcelona, Gedisa, 2016.

Taylor, Ch., A Secular Age, Cambridge, Mass., Harvard Uni. Press, 2007.

Zohar: el libro del esplendor (selección), tr. Carlos Giol, Barcelona, Obelisco, 2012. 